\title{
Progression of diet induced nonalcoholic steatohepatitis is accompanied by increased expression of kruppel-like-factor 10 in mice
}

\author{
Ja Kyung Kim', Kwan Sik Lee ${ }^{1}$, Hye Young Chang ${ }^{2}$, Woon Kyu Lee ${ }^{3}$ and Jung II Lee ${ }^{\text {1* }}$
}

\begin{abstract}
Background: Kruppel-like-factor (KLF) 10 is identified as transforming growth factor (TGF) $\beta$ inducible early gene and is reported to suppress lipogenic genes. Although previous studies report that TGF $\beta$ plays an important role in progression of nonalcoholic steatohepatitis (NASH) by regulating liver fibrosis, the association of KLF10 and NASH has never been explored. Thus we evaluated expressions and changes of KLF10 in diet induced NASH and in NASH which was alleviated by ursodeoxycholic acid (UDCA). We also assessed KLF10 in quiescent and activated hepatic stellate cells (HSCs).
\end{abstract}

Methods: C57BL/6 mice were given high fat, sucrose diet (HFSD) at least for 12 weeks up to 48 weeks and sacrificed at 12, 24 and 48 weeks thereafter. In other groups, either standard diet (SD) or HFSD was given for 24 weeks at which point mice fed with HFSD were divided into two groups, and were given either UDCA in combination with HFSD or vehicle with HFSD. Mice under SD were given vehicle. HSCs were isolated from C57BL/6 mice in order to evaluated KLF10 expression in activated HSCS.

Results: The mice were found to acquire liver steatosis and inflammation starting from week 12 of HFSD feeding, although significant liver fibrosis was noticed by week 24. Increased TGF $\beta$ and collagen al (I) (Co/la(I)) expression was also apparent from week 24. However, expression of KLF10 mRNA started to increase from week 12, earlier than TGF $\beta$ gene. Up-regulation of KLF10 was accompanied by suppressed carbohydrate response element-binding protein (ChREBP) that is known to be protective against insulin resistance. The mice fed with HFSD and UDCA had decreased Cola(l) mRNA that was coincided with reduced TGF $\beta$ and KLF10 expression. Expression of ChREBP was also recovered by UDCA administration. Enhanced KLF10 was noticed in activated HSCs when quiescent cell showed minimal expression.

Conclusions: Our study demonstrated that KLF10 expression was significantly increased in diet induced NASH and collagen producing activated HSCs. We also noticed that this up-regulation of KLF10 was accompanied by increased TGF $\beta$ signaling genes and suppressed ChREBP expression. These observations suggest possible association of KLF10 and NASH progression.

\section{Introduction}

Nonalcoholic fatty liver disease (NAFLD) is the most prevalent chronic liver disease worldwide, ranging from simple steatosis to steatohepatitis [1-3]. Unlike simple steatosis, nonalcoholic steatohepatitis (NASH) is characterized by hepatocellular injury with inflammation and fibrosis that can progress to liver cirrhosis [4]. The

\footnotetext{
* Correspondence: mdflorence@yuhs.ac

'Department of Internal Medicine, Gangnam Severance Hospital, Yonsei University College of Medicine, 211 Eunju-ro, Gangnam-gu, Seoul 135-720, Republic of Korea

Full list of author information is available at the end of the article
}

presence of fibrosis and its severity is reported to be the most important prognostic factor [5-7].

Studies on the intriguing mechanism of liver fibrosis identify transforming growth factor (TGF) $\beta$ as a key regulator of fibrosis [8-11]. However, being a multifunctional cytokine which regulates cell survival, differentiation, migration as well as extracellular matrix production $[12,13]$, targeting TGF $\beta$ itself in treating liver fibrosis may accompany detrimental adverse effects. Studies on the signaling of TGF $\beta$ reveal that once it binds to a receptor which is then phosphorylated, subsequent intracellular signaling pathway including Smad proteins would activate [14]. In addition, TGF $\beta$ can induce immediate 
early response transcription factors such as Kruppel-likefactors (KLF) that would work as effector proteins $[15,16]$.

KLF10, which is initially identified from osteoblastic cell population [17], is known to be regulated by TGF $\beta$ / Smad pathway. KLF10 may induce transcription of Smad2 and repress Smad7 [18-20]. It exerts its function as modulating differentiation markers, suppressing proliferation and inducing apoptosis of cells $[18,21,22]$. A recent study reports that KLF10 can also suppress lipogenic genes and that glucose stimulation induces KLF10 mRNA expression, suggesting the possible role of KLF10 on glucose and lipid metabolism [23], two important pathways in relation to nonalcoholic fatty liver disease.

Regarding glucose and lipid metabolism, carbohydrate response element-binding protein (ChREBP) is known to induce the expression of lipogenic and glycolytic genes in response to the glucose stimulation [24,25]. Interestingly, overexpression of ChREBP in mice fed with high fat diet showed improved insulin resistance despite the greater hepatic steatosis [26]. On the other hands, ChREBP overexpression induces KLF10 mRNA expression in rat hepatocytes whereas KLF10 overexpression partially suppressed ChREBP target genes [27].

KLF10 and its association with NASH have never been studied. Here, we used diet which was high in fat and sucrose to induce NASH and evaluated the expression of KLF10 in the liver. We also evaluated the change of KLF10 when diet induced NASH was alleviated after giving ursodeoxycholic acid (UDCA). Since our observations suggested that KLF10 expression increased with progression of NASH fibrosis and repressed as fibrosis regressed, in vitro study using primarily cultured hepatic stellate cells (HSCs), key players of liver fibrosis, was done. Extracellular matrix (ECM) producing activated HSCs showed increased KLF10 expression when compared with that of quiescent HSCs. We additionally identified that expression of ChREBP was suppressed in $\mathrm{NASH}$ and KLF10 expression was inversely coincided with $C h R E B P$ in the liver.

\section{Materials and methods}

\section{Animals and experimental design}

The animal experimental procedures and protocols were approved by the Institutional Animal Care and Use Committee (IACUC) of Gangnam Severance Hospital, Yonsei University College of Medicine (Permit Number: 0173). The study was carried out in accordance with the recommendation and restrictions of IACUC.

C57BL/6 male mice (8 weeks of age) were obtained from the Central Lab Animal (Seoul, Korea) and housed with a 12-h light-dark cycle. Zeitgeber time zero (ZT0) referred to the time of lights on. Mice were fed with either a standard chow (standard diet, SD) or a diet high in saturated fat, cholesterol and sucrose, termed as high fat and sucrose diet (HFSD). HFSD, purchase from Picolab (Bethlehem, PA), was consisted of $15 \%$ anhydrous milkfat, $1.0 \%$ cholesterol, and $50 \%$ sucrose. SD or HFSD was given at least for 12 weeks up to 48 weeks and the mice were sacrificed at 12,24 , or 48 weeks after the feeding. In other groups of mice, either SD or HFSD was given for 24 weeks at which point the mice fed with HFSD were divided into two groups. For mice under HFSD, one group was fed with HFSD in combination with $20 \mathrm{mg} / \mathrm{kg}$ UDCA diluted in $0.78 \%$ Tween-80 which was administered orally through sonde for 24 weeks and the other group of mice was given $0.78 \%$ Tween- 80 with HFSD. For mice under SD, $0.78 \%$ Tween- 80 was also given for 24 weeks. These groups of mice were sacrificed and the liver harvested at 24 weeks after the feeding of the experimental agents with either HFSD or SD. All the mice were sacrificed at ZT8 and a portion of fresh liver tissue was fixed in $10 \%$ buffered formalin, with the remaining tissue snap-frozen in liquid nitrogen and stored at $-80^{\circ} \mathrm{C}$. Blood samples were collected after anesthetized by cardiac puncture, and stored at $-80^{\circ} \mathrm{C}$.

\section{Histology}

Sections of liver tissue specimens, fixed in 10\% formalin and embedded in paraffin wax, were stained with $H \& E$ and Sirus red for histological examination. A blinded investigator evaluated the slides for fatty change, inflammation, existence of hepatocyte ballooning, and fibrosis as described in previous studies with minor modifications [28-30]. Degree of steatosis was scored as the percentage of hepatocytes containing macrovesicular fat (grade 0: no steatosis, grade $1:<25 \%$, grade $2: 26-50 \%$, grade $3: 51-75 \%$, grade $4: 76-100 \%)$. Inflammation was histologically quantified by counting inflammatory foci in 20 consecutive high-power fields (X40 objective) (average histological grade, grade 0 : no foci, grade $1:<2$ foci per high-power field, grade $2: \geq 2$ foci per high-power field). The individual scores of steatosis, inflammation and hepatocyte ballooning were added to produce an overall score, namely 'NAFLD Activity Score' (NAS) as previously suggested [30]. Fibrosis scores were as follows: 1, pericellular and perivenular fibrosis; 2 , focal bridging fibrosis; 3 , bridging fibrosis with lobular distortion; and 4, cirrhosis.

\section{HSC isolation and culture}

HSCs were isolated from C57BL/6 male mice (16-18 weeks of age) by pronase/collagenase perfusion and density centrifugation methods using Nycodez [31,32]. Isolated HSCs were either placed and stored at $-80^{\circ} \mathrm{C}$ in order to evaluate HSC at quiescent stage, or cultured on uncoated tissue culture dishes $\left(1-4 \times 10^{4} \mathrm{cells} / \mathrm{cm}^{2}\right)$ in DMEM supplemented with $10 \% \mathrm{FBS}$ and penicillin in $95 \%$ air $5 \% \mathrm{CO}_{2}$ humidified atmosphere at $37^{\circ} \mathrm{C}$ for culture activation. The culture activated HSCs were harvested after 7 days. 
HSCs were isolated from three mice for each quiescent and culture activated group.

\section{RNA extraction and gene expression analysis by quantitative real-time polymerase chain reaction (PCR)}

Total RNA was extracted from frozen whole liver or isolated HSCs using Trizol reagent (Invitrogen, Carlsbad, CA, USA) or Qiagen mini columns (Quiagen Inc. Valencia, CA, USA) according to the manufacturer's protocol. RNA samples were quantified by spectrophotometry. The RNA integrity was assessed using agarose gel electrophoresis and ethidium bromide staining. The RNA samples were then diluted in RNase-free water and stored at $-70^{\circ} \mathrm{C}$ until use. Five micrograms of RNA were reverse-transcribed using RNA PCR kit version 1.2 (Takara Bio Inc, Japan) according to the manufacturer's recommendations. Oligonucleotide primers and TagMan probe for KLF10, TGF $\beta$, Smad 2, 3, 7, tumor necrosis factor (TNF) $\alpha$, ChREBP, sterol regulatory element binding protein (SREBP)-1c, collagen $\alpha 1(I)(\operatorname{Col} 1 \alpha(I))$ and smooth muscle $\alpha$-actin $(\alpha \mathrm{SMA})$ were used with $18 \mathrm{~S}$ as internal control. The probes were obtained from Applied Biosystems (Perkin-Elmer/PE Applied Biosystems, Forster City, CA, USA), purchased as a ready-for-use form in Assays-on-Demand Gene Expression Products. The TaqMan probes were labeled at the 5' end with the reporter dye FAM and minor groove binder (MGB) nonfluorescent quencher on the 3'end. The quantitative PCR was performed in triplicate for each sample on Step One Plus Real Time System (Applied Biosystems). Each $20-\mu \mathrm{L}$ reaction contained $10 \mathrm{uL}$ of TaqMan Fast Universal Master Mix (Applied Biosystems, Darmstadt, Germany), $1 \mathrm{uL}$ of Gene Expression Mix and $2 \mathrm{uL}$ of cDNA diluted in $7 \mu \mathrm{L}$ RNase-free water. The thermal cycler conditions were 20 seconds at $95^{\circ} \mathrm{C}, 40$ cycles of 5 seconds at $95^{\circ} \mathrm{C}$ followed by 20 seconds at $60^{\circ} \mathrm{C}$. mRNA fold changes in target genes relative to the endogenous $18 \mathrm{~S}$ control were calculated as suggested on previous studies [33].

\section{Protein extraction and immunoblotting}

Whole liver protein lysates were extracted using a Triton$\mathrm{X} 100$ lysis buffer with protease inhibitors, and quantified using the Bradford method with BSA [34]. SDS-PAGE analysis of proteins levels was determined by means of immunoblotting using mouse anti-Klf10 (Santa Cruz, Santa Cruz, CA), and rabbit anti- $\beta$-actin conjugated to HRP (Cell Signaling Technology Inc., Trask Lane Danvers, MA). Epitope-primary antibody complexes were detected with species-specific secondary antibodies conjugated to HRP followed by ECL (Thermo Fisher Scientific Pierce, Illinois). Autoradiograms of blots were scanned and quantified using an image processor program (ImageJ from National Institute of Health). $\beta$-actin was used as a loading control.

\section{Measurement of liver 4-hydroxynonenal (HNE)-protein adducts in mice liver}

A quantitative OxiSelect HNE-His Adduct enzyme-linked immunosorbent assay kit (Cell Biolabs, San Diego, CA, USA) was used for determination of HNE-protein adducts according to the manufacturer's instruction. Briefly, bovine serum albumin standards or protein extracts from the liver tissues $(10 \mu \mathrm{g} / \mathrm{mL})$ were absorbed onto a 96-well plate overnight at $4^{\circ} \mathrm{C}$. After washing $100 \mu \mathrm{L}$ diluted anti-4-HNE-His antibody (1:1000) was added to each well and incubated for 1 hour at room temperature, followed by incubation with $100 \mu \mathrm{L}$ of horseradish peroxidaseconjugated secondary antibody (1:1000) for an hour. After washing, $100 \mu \mathrm{L}$ of substrate solution was added and then the reaction was stopped by adding $100 \mu \mathrm{L}$ of stop solution after 10 minutes. The absorbance was measured at $450 \mathrm{~nm}$ on a microplate reader. The 4-HNE-protein adducts content in the protein samples is determined according to a standard curve prepared from predetermined 4-HNE-bovine serum albumin standards.

\section{Statistical analysis}

All the results are presented as means \pm standard error of mean (SEM). Data were analyzed by nonparametric analysis (Kruskal-Wallis or Mann-Whitney test) or oneway ANOVA with Tukey's post hoc analysis. $P<0.05$ was considered statistically significant. All calculations were performed with SPSS version 15.0 software (SPSS Inc., Chicago, IL, USA).

\section{Results}

Aging did not affect the expression of KLF10 in the liver Since a recent study reported that aging promoted diet induced NASH in mice [35], expression of KLF10 mRNA in the liver was compared among the liver specimens of mice fed with SD for 12,24 and 48 weeks $(n=8$, for each ages). There was no statistically significant difference in KLF10 expression by aging $(P=0.393)$ (Figure $1 \mathrm{~A})$. Expression of TGF $\beta$, Smad7, 2, 3, TNF $\alpha, \operatorname{Col} 1 \alpha(I)$ and ChREBP mRNA were also tested at different age groups. These genes all demonstrated no significant changes by aging (data not shown).

\section{Administration of HFSD induced NASH}

Eight week old mice were fed with HFSD at least for 12 weeks up to 48 weeks and the mice were sacrificed at 12,24 , or 48 weeks after feeding ( $\mathrm{n}=8$ for each groups) at ZT8. Mice which were given SD for 12 weeks served as control. Body weights and serum biochemical findings are summarized in Table 1. Feeding HFSD for 48 weeks resulted in increased serum cholesterol levels $(\mathrm{P}=0.043)$. Giving HFSD for 24 weeks demonstrated significantly elevated serum ALT levels $(\mathrm{P}=0.029)$ which worsened after 48 weeks of treatment $(\mathrm{P}=0.000$ when compared 


\section{A}

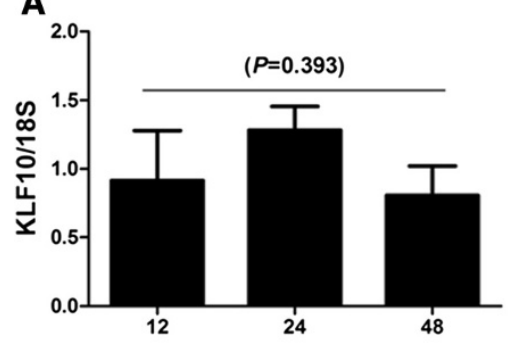

C

Age after SD (Weeks)

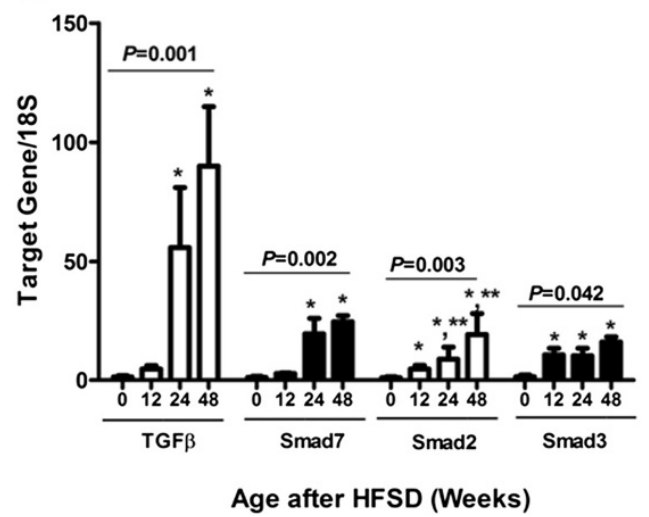

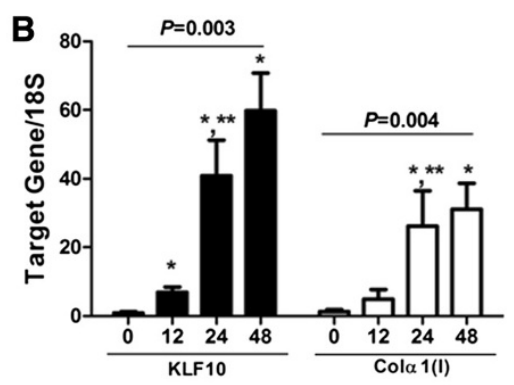

Age after HFSD (Weeks)

D

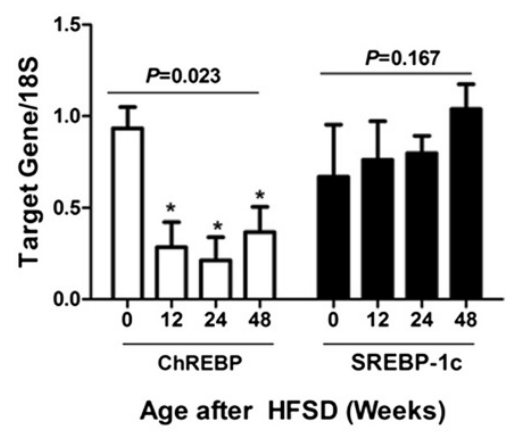

Figure 1 Changes in KLF10 and other associated gene expression in diet induced NASH. C57BL/6 mice were fed with high fat, sucrose diet (HFSD) and sacrificed at 12, 24, or 48 weeks after the feeding. Mice that were given standard diet (SD) for 12 weeks served as control. A, KLF10 mRNA expression in the liver of SD fed mice showed no significant changes according to their age when test at the age of 12,24 , and 48 weeks after SD feeding $(P=0.393)$. B, Significant up-regulation of KLF10 mRNA was observed by week 12 and thereafter when compared with the mice fed with SD which served as control $(P=0.003)$. Expression of Cola $(I)$ mRNA significantly increased at week 24 and $48(P=0.004)$ when compared with that of mice fed with SD for 12 weeks. C, Significant increase of TGF $\beta$ mRNA was detected from week 24 and it progressed at week $48(P=0.001)$. Downstream Smad 2, and 3 also increased as fibrosis progressed although significant increase of Smad $2(P=0.003)$ and $3(P=0.042)$ were demonstrated as early as week 12. Inhibitory Smad7 increased from week $24(P=0.002)$. $\mathbf{D}$, Expression of ChREBP which is reported to have a protective effect on insulin resistance, decreased with HFSD feeding, although the change was not related with either the duration of HFSD feeding or the severity of NASH $(P=0.023)$. Expression of a lipogenic gene, SREBP-1C showed no significant change with HFSD feeding $(P=0.167)$. ${ }^{*} P<0.05$, when compared with that of mice fed with SD. ${ }^{*} P<0.05$ when compared with that of mice fed with HFSD for the shorter duration.

Table 1 Characterization of mice fed with HFSD ${ }^{\dagger}$

\begin{tabular}{|c|c|c|c|c|}
\hline Age diet & $12 S^{\ddagger}(n=8)$ & 12 HFSD $(n=8)$ & 24 HFSD $(n=8)$ & $48 \operatorname{HFSD}(n=8)$ \\
\hline Weight & $25.83 \pm 0.95$ & $30.76 \pm 3.32$ & $36.77 \pm 3.15$ & $46.8 \pm 2.41^{*}$ \\
\hline Serum glucose (mg/dL) & $125.00 \pm 35.60$ & $73.80 \pm 8.11$ & $54.33 \pm 3.67$ & $116.00 \pm 18.00$ \\
\hline Serum TG" (mg/dL) & $119.00 \pm 2.65$ & $83.20 \pm 14.11$ & $74.00 \pm 7.09$ & $124.00 \pm 7.23$ \\
\hline Serum $\mathrm{Chol}^{\dagger \dagger}(\mathrm{mg} / \mathrm{dL})$ & $82.33 \pm 4.07$ & $112.80 \pm 13.62$ & $136.67 \pm 27.84$ & $158.00 \pm 5.20^{*}$ \\
\hline Serum $A L T^{\ddagger \ddagger}(I U / L)$ & $25.00 \pm 3.05$ & $81.00 \pm 15.32$ & $123.33 \pm 24.25^{*}$ & $393.00 \pm 26.58^{*}$ \\
\hline
\end{tabular}

Data are expressed as mean \pm standard of error (SE).

${ }^{\dagger} \mathrm{HFSD}$, high fat and sucrose diet.

${ }^{\text {F }} \mathrm{SD}$, standard chow is considered as standard diet.

"TG, triglyceride.

${ }^{+\dagger}$ Chol, cholesterol.

${ }^{\ddagger \neq} \mathrm{ALT}$, alanine aminotransferase.

${ }^{*} P<0.05$, when compared with mice given SD.

Results with statistical significances are shown in bold letters. 
with the control; $\mathrm{P}=0.000$ when compared with that of week 24). Administration of HFSD induced liver inflammation and fibrosis, characteristics of NASH (Figure 2A). NAS was significantly increased from week 12 of HFSD feeding $(P=0.012)$ (Table 2). On the other hands, significant increase in fibrosis score was noticed from week 24 of HFSD feeding $(\mathrm{P}=0.004)$ (Table 2).

\section{Expression of liver KLF10 increased in HFSD induced NASH}

Expression of KLF10 in the liver significantly increased after 12 weeks of HFSD diet feeding compared with that of the mice fed with SD for 12 weeks which served as control (Figure 1B). However, KLF10 expression at week 48 did no show significant difference when compared with that at week $24(P=0.282)$. Administration of HFSD also showed increased expression of KLF10 protein that was evident after 24 weeks of feeding (Figure 3A,B). In accordance with histological analysis, hepatic $\operatorname{Col1} \alpha(I)$ mRNA expression increased by week 24 following the increase of Klf-10 expression (Figure 1B).

TGF $\beta$ mRNA increased in the liver although expression of Smad7 was not reduced in HFSD induced NASH

Since KLF10 is initially identified as a TGF $\beta$-inducible early gene (TIEG) and is known to act by repressing the inhibitory Smad 7 [36], we evaluated liver mRNA expression
Table 2 Nonalcoholic fatty liver disease (NAFLD) activity score (NAS) and fibrosis score of mice fed with HFSD ${ }^{\dagger}$

\begin{tabular}{lllll}
\hline Age diet & $\begin{array}{l}12 \mathrm{SD}^{\ddagger} \\
(\mathbf{n}=\mathbf{8})\end{array}$ & $\begin{array}{l}12 \mathrm{HFSD} \\
(\mathbf{n}=\mathbf{8})\end{array}$ & $\begin{array}{l}24 \mathrm{HFSD} \\
(\mathbf{n}=\mathbf{8})\end{array}$ & $\begin{array}{l}\text { 48 HFSD } \\
(\mathbf{n}=\mathbf{8})\end{array}$ \\
\hline $\mathrm{NAS}^{\S}$ & $0.00 \pm 0.00$ & $3.20 \pm 0.49^{*}$ & $\mathbf{7 . 3 3} \pm 0.33^{*}$ & $\mathbf{6 . 8 3} \pm 0.31^{*}$ \\
Fibrosis & $0.00 \pm 0.00$ & $0.02 \pm 0.20$ & $\mathbf{2 . 0 0 \pm 0 . 0 0 *}$ & $\mathbf{2 . 4 2} \pm 0.08^{* * * * *}$
\end{tabular}

Data are expressed as mean \pm standard of error (SE).

${ }^{+} \mathrm{HFSD}$, high fat and sucrose diet.

${ }^{\ddagger} \mathrm{SD}$, standard chow is considered as standard diet

SNAS, nonalcoholic fatty liver disease activity score, which is the summation of the pathologic scores for steatosis, inflammation and hepatic ballooning. ${ }^{*} P<0.05$, when compared with mice given HFSD.

${ }^{* *} P<0.05$, when compared with mice given HFSD for 24 weeks.

Results with statistical significances are shown in bold letters.

of TGF $\beta$, Smad7 as well as $\operatorname{Smad} 2$ and 3. Hepatic TGF $\beta$ mRNA expression increased from week 24 of HFSD feeding when KLF10 mRNA expression started to increase from week 12 (Figure 1C). Smad 2 and 3, that are downstream mediators of TGF $\beta$ were evaluated. Although both Smad 2 and 3 started to increase from week 12 of HFSD administration, Smad3 expression was not affected by the length of HFSD feeding when Smad2 expression augmented as the duration of HFSD feeding prolonged (Figure 1C). Even with the increased KLF10 expression, inhibitory $\operatorname{Smad} 7$ also increased from week 24 and thereafter (Figure 1C).
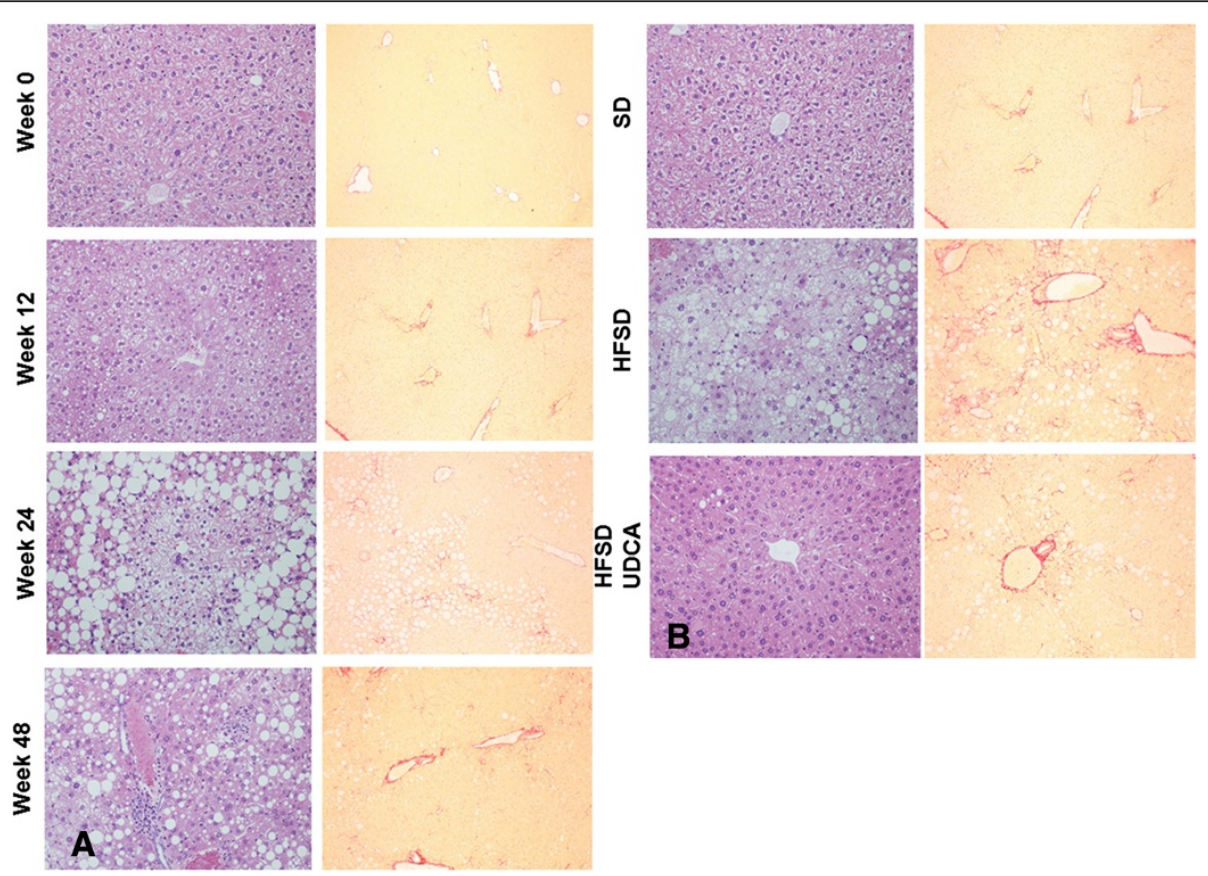

Figure 2 Histological assessment of inflammation and fibrosis in diet induced NASH. Histological analysis of the liver evaluating fatty change, inflammation, existence of hepatocyte ballooning and fibrosis was performed after H\&E (X200) and Sirus red (X100) staining. A, Representative histological evaluation of mice fed with high fat, sucrose diet (HFSD). Liver specimens were obtained at 12, 24, or 48 weeks after the feeding. Mice fed with standard diet (SD) for 12 weeks served as the control. B, Representative histological assessment of mice fed with SD, HFSD and HFSD in combination with ursodeoxycholic acid (UDCA). Mice were fed with HFSD for 24 weeks and divided into two groups, from which one group was given HFSD with vehicle, and the other group was given HFSD with UDCA for another 24 weeks. Mice fed with SD and vehicle for 48 weeks served as the control. 

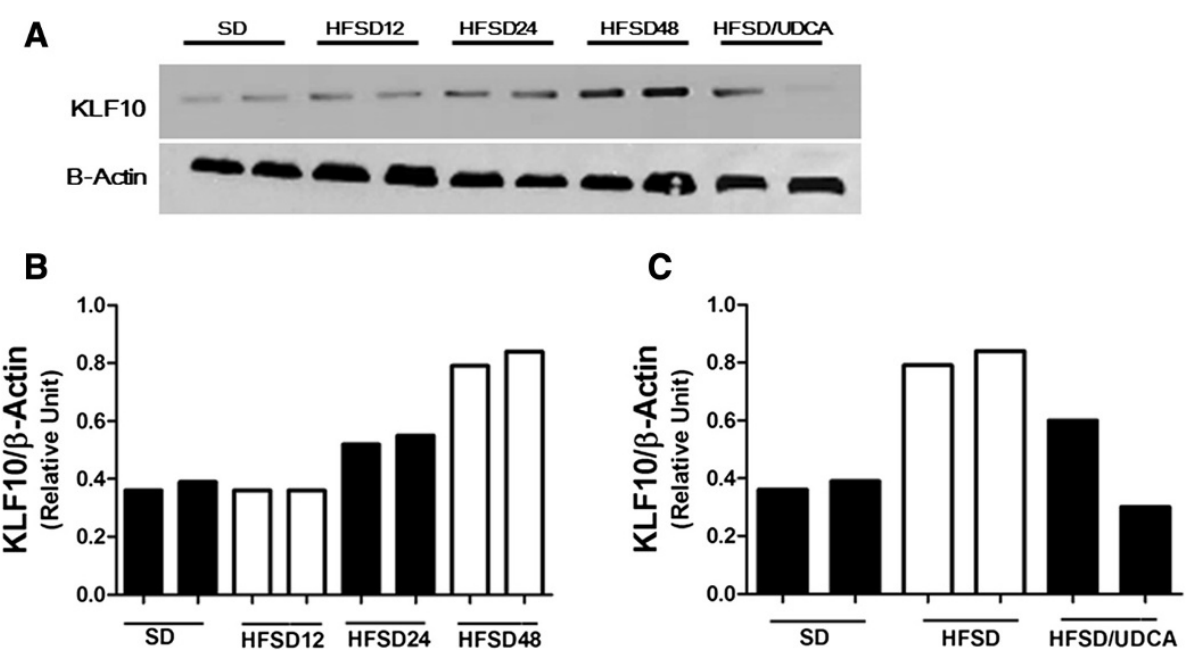

Figure 3 Changes in KLF10 protein. Western blot analysis of KLF10 was performed with $\beta$-actin antibody as a loading control. Autoradiogram of the blot was scanned and quantified using an image processor program. A representative Western blot and the result of quantitative analysis are shown. A, A representative Western blot autoradiogram B, KLF10 protein increased after 24 weeks of high fat, sucrose diet (HFSD24) feeding and more so after 48 weeks of feeding (HFSD48). Mice that were given standard diet is designated as SD. C, KLF10 protein which was increased after 48 weeks of HFSD feeding, was attenuated when ursodeoxycholic acid (UDCA) was given with HFSD (HFSD/UDCA).

\section{Expression of ChREBP was suppressed with increase of KLF10 expression in HFSD induced NASH}

It is reported that overexpression of ChREBP induces KLF10 whereas KLF10 overexpression partially suppresses ChREBP target genes in hepatocytes [27]. We were curious how ChREBP would behave when KLF10 expression increased in HFSD induced NASH. Feeding HFSD resulted in suppressed ChREBP mRNA expression although the reduction rate did not correlate with the duration of HFD administration (Figure 1D). Another lipogenic gene, SREBP-1c was tested and demonstrated no definite difference in hepatic expression after HFSD administration (Figure 1D).

\section{Concurrent administration of UDCA and HFSD resulted in decreased Cola1(I) mRNA expression that coincided with reduction of $K L F 10$}

UDCA is reported to be beneficial in experimental NASH $[37,38]$. Therefore we investigated whether adding UDCA to HFSD would facilitate alleviation of NASH and be accompanied by changes in KLF10 as well as other NASH associated genes. Mice were fed with HFSD for 24 weeks and divided into two groups. They were given either HFSD with vehicle or HFSD with UDCA for another 24 weeks. Mice that were given SD received vehicle and served as control. Body weights and serum biochemical findings are summarized in Table 3. Giving HFSD resulted in increased body weight, serum cholesterol and ALT levels, and adding UDCA reversed the effect of HFSD. Pathological evaluation revealed that concurrent administration of UDCA and HFSD had decreased NAS even though improvement in fibrosis score was not evident (Table 4) (Figure 2B). Administration of UDCA with HFSD showed diminished Col1 $\alpha(I)$ mRNA expression which also coincided with decreased hepatic KLF10 and TGF $\beta$ mRNA (Figure 4A). Attenuated expression of KLF10 could also be detected on protein level after concurrent feeding of UDCA and HFSD (Figure 3A,C).

\section{UDCA significantly decreased the expression of NASH} associated genes

Giving UDCA with HFSD could reverse the expression of Smad 2 and Smad3 mRNA in the liver. However, UDCA also attenuated the expression of inhibitory Smad7 (Figure 4B). Expression of ChREBP mRNA which was reduced by HFSD feeding was recovered by adding UDCA to HFSD (Figure 4C).

Expression of pro-inflammatory cytokine $T N F \alpha$ is reported to be increased in NASH [39]. UDCA administration alleviated increased $T N F \alpha$ mRNA expression (Figure 4D) in accordance with the result of histological analysis (Table 4) (Figure 1B).

\section{Effect of UDCA on NASH was not associated with decreased HNE protein adducts}

Protective effect of UDCA on liver injury is frequently reported to be associated with relieving oxidative stress [38,40-42]. We evaluated whether beneficial effect of UDCA on NASH in our study was associated with decreased aldehyde-protein adduct formation, a consequence of the oxidative stress [43]. However, increased 4-HNE protein adducts by feeding HFSD was not significantly reduced by concomitant administration of UDCA (Figure 5). 
Table 3 Characterization of mice given $\mathrm{HFSD}^{\dagger}$ with or without UDCA ${ }^{\ddagger}$

\begin{tabular}{|c|c|c|c|}
\hline Age diet & $48 S^{\S}(n=8)$ & 48 HFSD $(n=8)$ & 48 HFSD/UDCA $(n=8)$ \\
\hline Weight & $35.33 \pm 1.45$ & $46.8 \pm 2.41 *$ & $43.05 \pm 1.42$ \\
\hline Serum glucose (mg/dL) & $366.00 \pm 56.04$ & $116.00 \pm 18.00$ & $132.67 \pm 0.88$ \\
\hline Serum TG" (mg/dL) & $180.67 \pm 13.96$ & $124.00 \pm 7.23$ & $107.33 \pm 28.03$ \\
\hline Serum $\mathrm{Chol}^{+\dagger}(\mathrm{mg} / \mathrm{dL})$ & $89.33 \pm 6.77$ & $158.00 \pm 5.20^{*}$ & $121.00 \pm 16.44$ \\
\hline Serum $A_{L} T^{\neq \neq}(I \cup / L)$ & $70.00 \pm 14.19$ & $393.00 \pm 26.58^{*}$ & $87.33 \pm 11.57$ \\
\hline
\end{tabular}

Data are expressed as mean \pm standard of error (SE).

${ }^{\dagger} \mathrm{HFSD}$, high fat and sucrose diet.

${ }^{\ddagger}$ UDCA, ursodeoxycholic acid.

${ }^{\S} \mathrm{SD}$, standard chow is considered as standard diet.

"TG, triglyceride.

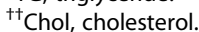

${ }^{\ddagger \neq} \mathrm{ALT}$, alanine aminotransferase.

* $P<0.05$, when compared with mice given SD.

Results with statistical significances are shown in bold letters.

\section{HSC activation was accompanied by increased KLF10 expression}

HSCs are the major cellular component of liver fibrosis by producing ECM and collagen [44]. The profibrogenic capacity of HSCs is eminent when they are activated. Since our study demonstrated that increased KLF10 coincided with progression of liver fibrosis, we evaluated if KLF10 expression was associated with HSC activation. Primarily isolated HSCs were culture activated and expression of KLF1O mRNA was evaluated along with aSMA, a marker for HSC activation. Primarily isolated HSCs without culture activation served as control. Expression of $\alpha S M A$ was increased in activated HSCs when it was hardly detected in quiescent cells (Figure 6A). In accordance with QSMA, expression of KLF10 increased in activated HSCs (Figure 6B).

\section{Discussion}

A pleiotropic cytokine TGF $\beta$ is well known for its profibrogenic effect through HSC in the liver [44]. Role of TGF $\beta$ signaling in progression of NASH associated fibrosis is also reported in several studies, making it an attractive target for the treatment $[45,46]$. Moreover, a study reported that TGF $\beta /$ Smad signaling is involved in

Table 4 Effect of ursodeoxycholic acid (UDCA) administration on diet induced nonalcoholic fatty liver disease (NAFLD) activity score (NAS) and fibrosis score

\begin{tabular}{|c|c|c|c|}
\hline Age diet & $48 \mathrm{SD}^{\dagger}(\mathrm{n}=8)$ & $48 \mathrm{HFSD}^{\ddagger}(n=8)$ & 48 HFSD/UDCA $(n=8)$ \\
\hline$\overline{N A S^{\S}}$ & $0.00 \pm 0.00$ & $8.17 \pm 0.40^{*}$ & $4.00 \pm 0.44^{* * * *}$ \\
\hline Fibrosis & $0.00 \pm 0.00$ & $2.42 \pm 0.08^{*}$ & $2.07 \pm 0.53^{*}$ \\
\hline
\end{tabular}

Data are expressed as mean \pm standard error (SE).

${ }^{\dagger} \mathrm{SD}$, standard chow is considered as standard diet.

${ }^{\ddagger} \mathrm{HFSD}$, high fat and sucrose diet.

${ }^{\S} \mathrm{NAS}$, nonalcoholic fatty liver disease activity score, which is the summation of the pathologic scores for steatosis, inflammation and hepatic ballooning.

${ }^{*} P<0.05$, when compared with mice given SD.

${ }^{*} P<0.05$, when compared with mice given HFSD.

Results with statistical significances are shown in bold letters. regulating insulin gene and suggested its role in the development of insulin resistance $[47,48]$. Smad3 deleted mice are protected from insulin resistance and high fat diet induced obesity [49]. When TGF $\beta$ receptor type II is selectively deleted in hepatocytes of mice, the mice would be resistant to diet induced NASH and fibrosis [50]. Although evidences suggest that blocking TGF $\beta$ would be beneficial for NASH, targeting TGF $\beta$ at the receptor level is probably not recommendable considering the multi-functional role of TGF $\beta$. Systemic mutation of TGF- $\beta_{1}$ is found to be lethal [51]. More studies may be required in order to find targets that would alleviate the adverse effects of TGF $\beta$ with minimal influence on the critical and beneficial role of the cytokine.

KLF10 is originally named as TIEG, which would increase about 30 minutes after TGF $\beta$ treatment and rapidly return to the normal level within 2 hours [52]. Turnover of KLF10 and its subsequent role can be regulated by its proteasomal degradation, and this can modulate TGF $\beta /$ Smad-dependent transcriptional activity [53]. KLF10 suppresses cell proliferation, induce apoptosis, and modulate immune system [18,21,22,54]. Although KLF10 deficient mice are reported to grow and reproduce normally [55], these mice demonstrate defects in healing potential [56,57], and abnormally enhanced $\mathrm{T}$ cell function resulting in aggravated atherosclerosis [54]. A transcriptome profiling study using the liver of KLF10 deficient mice reveals that KLF10 has a significant role in regulating genes that are involved in lipid and carbohydrate metabolism [23]. ChREBP, which is also suspected to be modulated by KLF10 [27], is a transcription factor that is observed to play a protective role in insulin resistance although it would aggravate simple hepatic steatosis [26]. In our study where $\mathrm{NASH}$, instead of simple steatosis without inflammation, is induced by giving HFSD, liver expression of ChREBP significantly decreased and its expression recovered when NASH was alleviated by UDCA administration. Depression of ChREBP coincided with increase of KLF10 expression 


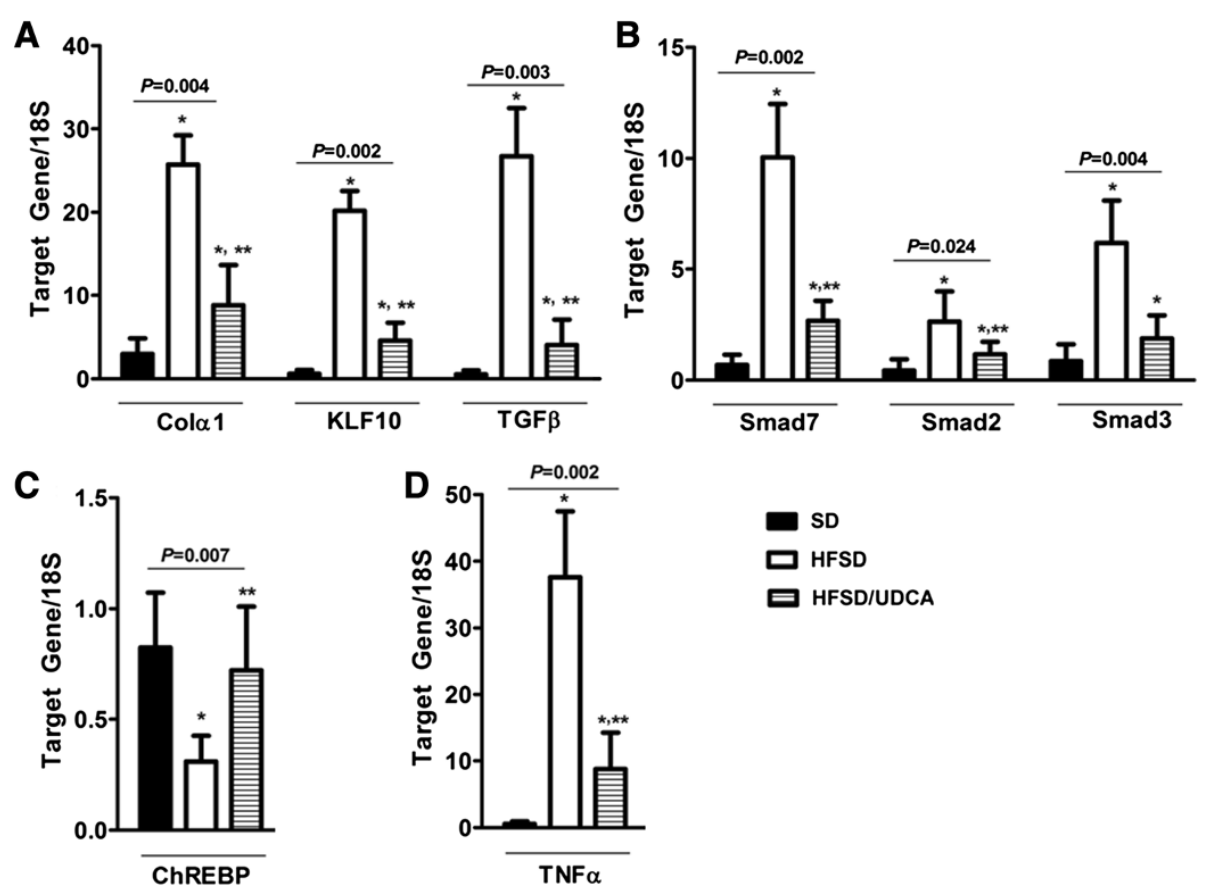

Figure 4 Decreased KLF10 mRNA expression and improved NASH upon UDCA administration with HFSD. C57BL/6 mice were fed with either standard diet (SD) or high fat, sucrose diet (HFSD) for 24 weeks upon which mice on HFSD were divided into two groups, and fed with either 20 mg/kg UDCA diluted in $0.78 \%$ Tween- 80 or $0.78 \%$ Tween-80 only. Mice fed with SD were also given $0.78 \%$ Tween-80 as vehicle. These three groups of mice namely SD with vehicle, HFSD with vehicle and HFSD with UDCA, were fed for another 24 weeks. Total RNA was extracted from the liver. A, Expression of Cola(l) mRNA was increased by HFSD feeding but reversed when HFSD was given in combination with UDCA $(P=0.004)$. KLF10 (P=0.002) along with TGF $\beta(P=0.003)$ mRNA expression also reduced upon UDCA administration with HFSD. B, TGF $\beta$ downstream signaling Smad $2(P=0.024)$, and $3(P=0.004)$ expression significantly diminished by UDCA feeding in combination with HFSD although inhibitory Smad7 $(P=0.002)$ also reduced when UDCA was given. C, Expression of ChREBP mRNA was decreased by HFSD feeding but partially recovered when UDCA was given in combination with HFSD $(P=0.007)$. D, Expression of inflammatory cytokine TNFa mRNA which was up-regulated by HFSD feeding, reduced by UDCA administration $(P=0.002)$. ${ }^{*} P<0.05$, when compared with that of mice fed with SD. ${ }^{* *} P<0.05$ when compared with that of mice fed with HFSD.

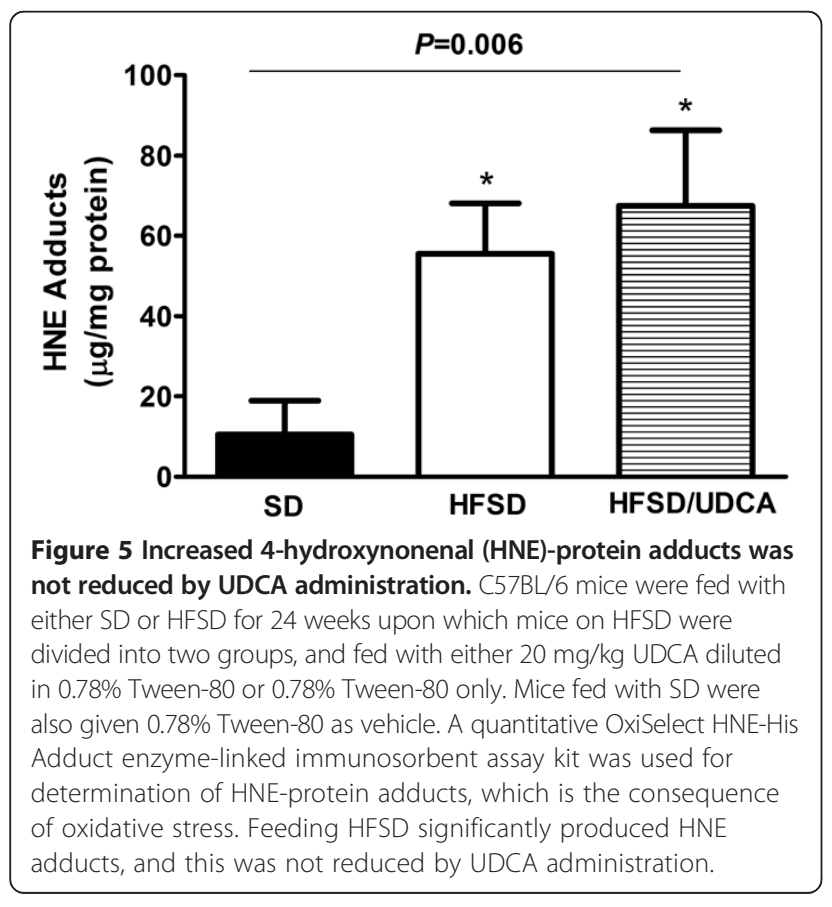

that correlated with enhanced TGF $\beta$ and Col1 $\alpha(I)$ mRNA expression that are signs of progressive liver fibrosis. A study where KLF10 is overexpressed in the hepatocytes demonstrates blunted ChREBP role in regulating carbohydrate metabolism [27], and it can be speculated that increased KLF1O along with attenuated ChREBP expression may have some association with progression of NASH.

In addition to liver fibrosis, it is well established that inflammation is also very important in development and progression of NASH $[30,39]$. Previous reports suggest the important role of KLF10 as a modulator of regulatory T cell function and deleting KLF10 demonstrates enhanced inflammatory reaction in cardiovascular system [54]. Although it is observed that high fat diet induced steatosis is accompanied by depletion of hepatic regulatory $\mathrm{T}$ cells [58], association of this regulatory $\mathrm{T}$ cell depletion and KLF10 has never been investigated. In our study, KLF10 up-regulation was coincided with increase in $T N F \alpha$ and worsening of histologically evaluated NAS, and the precise mechanistic role of KLF10 in inflammatory reaction of NASH should be sought in the future, possibly through a KLF10 deletion study. 

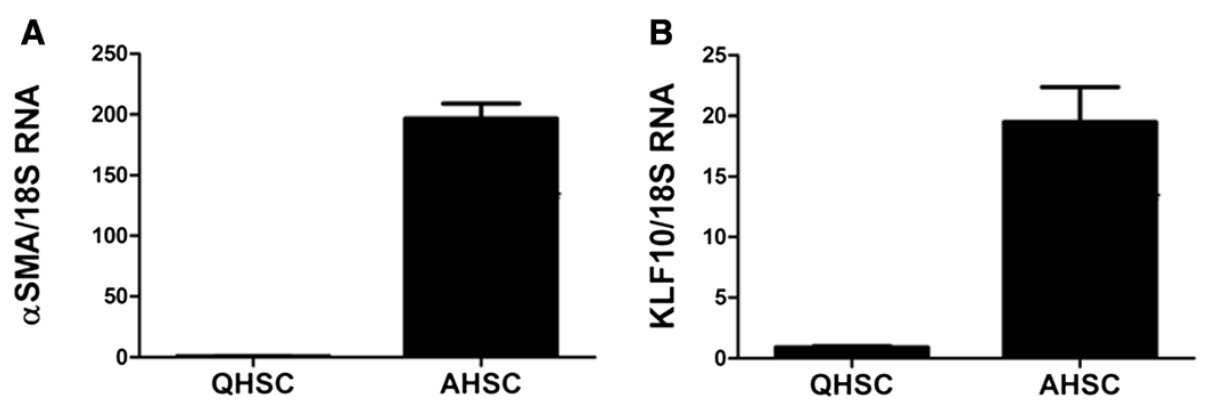

Figure 6 Expression of KLF10 in activated hepatic stellate cells (HSC). Primarily cultured HSCs were placed on a plastic dish for 7 days in order induced culture stimulated activation (AHSC). Quiescent HSCS (QHSC) without culture activation served as control. A, Quantification of aSMA mRNA, a sign of HSC activation, demonstrated the increased aSMA in activated HSCs when it was hardly detected in quiescent cells. B, Enhanced KLF10 mRNA was noticed in activated HSCs when minimal expression was visible in quiescent cells.

As stated earlier, KLF10 is known to be a TGF $\beta$ induced early gene which would rapidly return to the normal level within 2 hours after the stimulation. However, in the setting of HFSD induced NASH or culture activated HSCs, the insults are given repeatedly and these continuous stimulations may have resulted in chronic activation of KLF 10

Although clinical trials fail to show a meaningful effect of UDCA on alleviating NASH induced fibrosis, beneficial role of UDCA has been supported by several animal studies. These discrepancies may be explained by high UDCA dose used in animal studies that could hardly be achieved in humans [39]. Nevertheless, since the goal of our study was to investigate whether improvement in NASH would be accompanied by modulation of KLF10 expression, UDCA was used as a safe means of investigation. We observed that concurrent administration of UDCA and HFSD reduced Coll $\alpha(I)$ mRNA production. This improvement was accompanied by decreased KLF10 and TGF $\beta$ as well as recovered ChREBP expression in the liver, suggesting that enhanced KLF10 transcription might be related with NASH progression although the precise cause-and-effect mechanism should be delineated by another interventional study.

Our study revealed that activated HSCs were accompanied by increased KLF10 when KLF10 expression was negligible in quiescent HSCs. This finding still cannot explain whether KLF10 facilitates the progression of $\mathrm{NASH}$ fibrosis or the consequence of the liver fibrosis. However, it is worth noting that KLF10 expression is enhanced in ECM producing HSC.

The beneficial effects of UDCA on NASH can be explained by its anti-inflammatory, hepatoprotective effect as well as its role as an antioxidant $[38,41,59,60]$. Although our study showed significantly decreased TNF $\alpha$ expression after UDCA administration, it failed to show meaningful decrease in 4-HNE protein adducts, which is the consequence of oxidative insult. However, oxidative stress can be evaluated by multiple means and not having decreased
4-HNE protein adducts production cannot conclusively deny UDCA's role as an antioxidant in relieving NASH. Our study rather suggests that UDCA takes through multiple pathways in alleviating NASH.

\section{Conclusions}

To our knowledge, this is the first study that evaluated the expression of KLF10 in NASH and HSCs. Our study demonstrated that KLF10 expression was significantly increased in diet induced NASH and ECM producing activated HSCs. We also observed that this up-regulation of KLF10 was accompanied by increased TGF $\beta$ signaling genes and suppressed ChREBP expression which was known to improve insulin resistance. These observations may suggest possible association of KLF10 in progression of NASH. Further studies should be warranted to assess the specific role and mechanism of KLF10 in NASH associated liver fibrosis.

\section{Abbreviations}

NAFLD: Nonalcoholic fatty liver disease; NASH: Nonalcoholic steatohepatitis; TGF $\beta$ : Transforming growth factor $\beta$; KLF10: Kruppel-like-factor 10; TNFa: Tumor necrosis factor a; ChREBP: Carbohydrate response element-binding protein; SREBP-1c: Sterol regulatory element binding protein 1c; Col1a(I): Collagen a1(I); aSMA: Smooth mucle a-actin; UDCA: Ursodeoxycholic acid; ECM: Extracellular matrix; ZT: Zeitgeber time; HSC: Hepatic stellate cell; HFSD: High fat and sucrose diet; SD: Standard diet; NAS: Nonalcoholic fatty liver disease activity score; TIEG: TGF $\beta$ inducible early gene; HNE: Hydroxynonenal; SEM: Standard of mean.

\section{Competing interests}

The authors declare that they have no competing interest.

\section{Authors' contributions}

JK: study concept and design, data acquisition, drafting of manuscript. KSL: study concept and design, project coordination, data analysis, writing manuscript. HYC: processing of the experiment, data analysis. WKL: study concept, processing of the experiment especially regarding KLF10. JIL: obtainment of grant, study concept and design, analysis and interpretation of data, drafting of manuscript. All authors read and approved the final manuscript.

\section{Acknowledgements}

This study was financially supported by the "Dongwha Holdings" Faculty Research Assistance Program of Yonsei University College of Medicine for 2013 (6-2013-0066). 


\section{Author details}

'Department of Internal Medicine, Gangnam Severance Hospital, Yonsei University College of Medicine, 211 Eunju-ro, Gangnam-gu, Seoul 135-720, Republic of Korea. ${ }^{2}$ Medical Research Center, Gangnam Severance Hospital, 211 Eunju-ro, Gangnam-gu, Seoul 120-752, Republic of Korea. ${ }^{3}$ Laboratory of Developmental Genetics, Inha University School of Medicine, Incheon 400-712, Republic of Korea.

Received: 14 April 2014 Accepted: 24 June 2014

Published: 1 July 2014

\section{References}

1. Angulo P: GI Epidemiology: nonalcoholic fatty liver disease. Aliment Pharm Therap 2007, 25:883-889.

2. Argo CK, Caldwell SH: Epidemiology and natural history of non-alcoholic steatohepatitis. Clin Liver Dis 2009, 13:511-531.

3. Angulo P: Long-term mortality in nonalcoholic fatty liver disease: is liver histology of any prognostic significance? Hepatology 2010, 51:373-375.

4. Hubscher SG: Histological assessment of non-alcoholic fatty liver disease. Histopathology 2006, 49:450-465.

5. Harrison SA, Torgerson S, Hayashi PH: The natural history of nonalcoholic fatty liver disease: a clinical histopathological study. Am J Gastroenterol 2003, 98:2042-2047.

6. Fassio E, Alvarez E, Dominguez N, Landeira G, Longo C: Natural history of nonalcoholic steatohepatitis: a longitudinal study of repeat liver biopsies. Hepatology 2004, 40:820-826.

7. Adams LA, Sanderson S, Lindor KD, Angulo P: The histological course of nonalcoholic fatty liver disease: a longitudinal study of 103 patients with sequential liver biopsies. J Hepatol 2005, 42:132-138.

8. Bissell DM, Roulot D, George J: Transforming growth factor beta and the liver. Hepatology 2001, 34:859-867.

9. Sanderson N, Factor V, Nagy P, Kopp J, Kondaiah P, Wakefield L, Roberts AB, Sporn MB, Thorgeirsson SS: Hepatic expression of mature transforming growth-factor-beta-1 in transgenic mice results in multiple tissue lesions. Proc Natl Acad Sci U S A 1995, 92:2572-2576.

10. Kanzler S, Lohse AW, Keil A, Henninger J, Dienes HP, Schirmacher P, Rose-John S, zum Buschenfelde KH, Blessing M: TGF-beta1 in liver fibrosis: an inducible transgenic mouse model to study liver fibrogenesis. Am J Physiol 1999, 276:G1059-G1068.

11. Nakano S, Nagasawa T, Ijiro T, Inada Y, Tamura T, Maruyama K, Kuroda J, Yamazaki Y, Kusama H, Shibata N: Bezafibrate prevents hepatic stellate cell activation and fibrogenesis in a murine steatohepatitis model, and suppresses fibrogenic response induced by transforming growth factorbeta1 in a cultured stellate cell line. Hepatol Res Offic J Jpn Soc Hepatol 2008, 38:1026-1039.

12. Inagaki $Y$, Okazaki I: Emerging insights into Transforming growth factor beta Smad signal in hepatic fibrogenesis. Gut 2007, 56:284-292.

13. Dooley S, ten Dijke P: TGF-beta in progression of liver disease. Cell Tissue Res 2012, 347:245-256

14. Wells RG: Fibrogenesis. V. TGF-beta signaling pathways. Am J Physiol Gastrointest Liver Physiol 2000, 279:G845-G850.

15. Tachibana I, Imoto M, Adjei PN, Gores GJ, Subramaniam M, Spelsberg TC, Urrutia R: Overexpression of the TGFbeta-regulated zinc finger encoding gene, TIEG, induces apoptosis in pancreatic epithelial cells. J Clin Invest 1997 , 99:2365-2374

16. Cook T, Gebelein B, Mesa K, Mladek A, Urrutia R: Molecular cloning and characterization of TIEG2 reveals a new subfamily of transforming growth factor-beta-inducible Sp1-like zinc finger-encoding genes involved in the regulation of cell growth. J Biol Chem 1998, 273:25929-25936.

17. Fautsch MP, Vrabel A, Rickard D, Subramaniam M, Spelsberg TC, Wieben ED: Characterization of the mouse TGFbeta-inducible early gene (TIEG): conservation of exon and transcriptional regulatory sequences with evidence of additional transcripts. Mamm Genome Offic J Int Mamm Genome Soc 1998, 9:838-842.

18. Johnsen SA, Subramaniam M, Janknecht R, Spelsberg TC: TGFbeta inducible early gene enhances TGFbeta/Smad-dependent transcriptional responses. Oncogene 2002, 21:5783-5790.

19. Johnsen SA, Subramaniam M, Katagiri T, Janknecht R, Spelsberg TC: Transcriptional regulation of Smad2 is required for enhancement of TGFbeta/Smad signaling by TGFbeta inducible early gene. J Cell Biochem 2002, 87:233-241.
20. Hawse JR, Subramaniam M, Monroe DG, Hemmingsen AH, Ingle JN, Khosla S, Oursler MJ, Spelsberg TC: Estrogen receptor beta isoform-specific induction of transforming growth factor beta-inducible early gene- 1 in human osteoblast cells: an essential role for the activation function 1 domain Mol Endocrinol 2008, 22:1579-1595.

21. McConnell BB, Yang WW: Mammalian Kruppel-like factors in health and diseases. Physiol Rev 2010, 90:1337-1381.

22. Cook T, Urrutia R: TIEG proteins join the Smads as TGF-beta-regulated transcription factors that control pancreatic cell growth. Am J Physiol Gastrointest Liver Physiol 2000, 278:G513-G521.

23. Guillaumond F, Grechez-Cassiau A, Subramaniam M, Brangolo S, Peteri-Brunback B, Staels B, Fievet C, Spelsberg TC, Delaunay F, Teboul M: Kruppel-like factor KLF10 is a link between the circadian clock and metabolism in liver. Mol Cell Biol 2010, 30:3059-3070.

24. Uyeda K, Repa JJ: Carbohydrate response element binding protein, ChREBP, a transcription factor coupling hepatic glucose utilization and lipid synthesis. Cell Metab 2006, 4:107-110.

25. lizuka K, Horikawa Y: ChREBP: a glucose-activated transcription factor involved in the development of metabolic syndrome. Endocr J 2008, 55:617-624.

26. Benhamed F, Denechaud PD, Lemoine M, Robichon C, Moldes M, Bertrand Michel J, Ratziu V, Serfaty L, Housset C, Capeau J, Girard J, Guillou H, Postic C: The lipogenic transcription factor ChREBP dissociates hepatic steatosis from insulin resistance in mice and humans. J Clin Invest 2012, 122:2176-2194.

27. lizuka K, Takeda J, Horikawa Y: Kruppel-like factor-10 is directly regulated by carbohydrate response element-binding protein in rat primary hepatocytes. Biochem Biophys Res Commun 2011, 412:638-643.

28. Brunt EM: Nonalcoholic steatohepatitis: definition and pathology. Semin Liver Dis 2001, 21:3-16.

29. Kirsch R, Clarkson V, Shephard EG, Marais DA, Jaffer MA, Woodburne VE, Kirsch RE, Hall Pde L: Rodent nutritional model of non-alcoholic steatohepatitis: species, strain and sex difference studies. J Gastroenterol Hepatol 2003, 18:1272-1282

30. Kleiner DE, Brunt EM, Van Natta M, Behling C, Contos MJ, Cummings OW, Ferrell LD, Liu YC, Torbenson MS, Unalp-Arida A, Yeh M, McCullough AJ, Sanyal AJ: Design and validation of a histological scoring system for nonalcoholic fatty liver disease. Hepatology 2005, 41:1313-1321.

31. Weiskirchen R, Gressner AM: Isolation and culture of hepatic stellate cells. Meth Mol Med 2005, 117:99-113.

32. Maschmeyer P, Flach M, Winau F: Seven steps to stellate cells. J Visualized Exp: JOVE 2011

33. Livak KJ, Schmittgen TD: Analysis of relative gene expression data using real-time quantitative PCR and the 2(T)(-Delta Delta C) method. Methods 2001, 25:402-408

34. Campbell JS, Prichard L, Schaper F, Schmitz J, Stephenson-Famy A, Rosenfeld ME, Argast GM, Heinrich PC, Fausto N: Expression of suppressors of cytokine signaling during liver regeneration. J Clin Invest 2001, 107:1285-1292

35. Fontana L, Zhao EP, Amir M, Dong HQ, Tanaka K, Czaja MJ: Aging promotes the development of diet-induced murine steatohepatitis but not steatosis. Hepatology 2013, 57:995-1004.

36. Subramaniam M, Hawse JR, Rajamannan NM, Ingle JN, Spelsberg TC Functional role of KLF10 in multiple disease processes. Biofactors 2010 36:8-18

37. Pathil A, Mueller J, Warth A, Chamulitrat W, Stremmel W: Ursodeoxycholy lysophosphatidylethanolamide improves steatosis and inflammation in murine models of nonalcoholic fatty liver disease. Hepatology 2012, 55:1369-1378.

38. Mitsuyoshi H, Nakashima T, Sumida Y, Yoh T, Nakajima Y, Ishikawa H, Inaba K, Sakamoto Y, Okanoue T, Kashima K: Ursodeoxycholic acid protects hepatocytes against oxidative injury via induction of antioxidants. Biochem Biophys Res Commun 1999, 263:537-542.

39. Tilg H, Moschen AR: Evolution of inflammation in nonalcoholic fatty liver disease: the multiple parallel hits hypothesis. Hepatology 2010, 52:1836-1846

40. Okada K, Shoda J, Taguchi K, Maher JM, Ishizaki K, Inoue Y, Ohtsuki M, Goto N, Takeda K, Utsunomiya H, Oda K, Warabi E, Ishii T, Osaka K, Hyodo I, Yamamoto M: Ursodeoxycholic acid stimulates Nrf2-mediated hepatocellular transport, detoxification, and antioxidative stress systems in mice. Am J Physiol Gastrointest Liver Physiol 2008, 295:G735-G747

41. Uzun MA, Koksal N, Aktas S, Gunerhan Y, Kadioglu H, Dursun N, Sehirli AO: The effect of ursodeoxycholic acid on liver regeneration after partial hepatectomy in rats with non-alcoholic fatty liver disease. Hepatol Res Offic J Jpn Soc Hepatol 2009, 39:814-821. 
42. Sokolovic D, Nikolic J, Kocic G, Jevtovic-Stoimenov T, Veljkovic A, Stojanovic M, Stanojkovic Z, Sokolovic DM, Jelic M: The effect of ursodeoxycholic acid on oxidative stress level and DNase activity in rat liver after bile duct ligation. Drug Chem Toxicol 2013, 36:141-148.

43. Garcia-Ruiz I, Gomez-Izquierdo E, Diaz-Sanjuan T, Grau M, Solis-Munoz P, Munoz-Yague T, Solis-Herruzo JA: Sp1 and Sp3 transcription factors mediate leptin-induced collagen alpha $1(\mathrm{I})$ gene expression in primary culture of male rat hepatic stellate cells. Endocrinology 2012, 153:5845-5856.

44. Friedman SL: Mechanisms of hepatic fibrogenesis. Gastroenterology 2008, 134:1655-1669.

45. Cayon A, Crespo J, Mayorga M, Guerra A, Pons-Romero F: Increased expression of $\mathrm{Ob}-\mathrm{Rb}$ and its relationship with the overexpression of TGF-beta 1 and the stage of fibrosis in patients with nonalcoholic steatohepatitis. Liver Int 2006, 26:1065-1071.

46. Klein S, Mittendorfer B, Eagon JC, Patterson B, Grant L, Feirt N, Seki E, Brenner D, Korenblat K, McCrea J: Gastric bypass surgery improves metabolic and hepatic abnormalities associated with nonalcoholic fatty liver disease. Gastroenterology 2006, 130:1564-1572.

47. Lin HM, Lee JH, Yadav H, Kamaraju AK, Liu E, Duan ZG, Vieira A, Kim SJ, Collins $H$, Matschinsky F, Harlan DM, Roberts AB, Rane SG: Transforming growth factor-beta/Smad3 signaling regulates insulin gene transcription and pancreatic islet beta-cell function. J Bio/ Chem 2009, 284:12246-12257.

48. Tan CK, Leuenberger N, Tan MJ, Yan YW, Chen YH, Kambadur R, Wahli W, Tan NS: Smad3 deficiency in mice protects against insulin resistance and obesity induced by a high-fat diet. Diabetes 2011, 60:464-476.

49. Yadav H, Quijano C, Kamaraju AK, Gavrilova O, Malek R, Chen WP, Zerfas P, Duan ZG, Wright EC, Stuelten C, Sun P, Lonning S, Skarulis M, Sumner AE, Finkel T, Rane SG: Protection from obesity and diabetes by blockade of TGF-beta/Smad3 signaling. Cell Metab 2011, 14:67-79.

50. Yang L, Roh YS, Song J, Zhang B, Liu C, Loomba R, Seki E: Transforming growth factor beta signaling in hepatocytes participates in steatohepatitis through regulation of cell death and lipid metabolism in mice. Hepatology 2014, 59:483-495.

51. Boivin GP, Otoole BA, Orsmby IE, Diebold RJ, Eis MJ, Doetschman T, Kier AB: Onset and progression of pathological lesions in transforming growth factor-beta-1-deficient mice. Am J Pathol 1995, 146:276-288.

52. Subramaniam M, Harris SA, Oursler MJ, Rasmussen K, Riggs BL, Spelsberg TC: Identification of a novel TGF-beta-regulated gene encoding a putative zinc finger protein in human osteoblasts. Nucleic Acids Res 1995, 23:4907-4912.

53. Johnsen SA, Subramaniam M, Monroe DG, Janknecht R, Spelsberg TC: Modulation of transforming growth factor beta (TGF beta)/Smad transcriptional responses through targeted degradation of TGF beta-inducible early gene- 1 by human seven in absentia homologue. J Biol Chem 2002, 277:30754-30759

54. Cao ZX, Wara AK, Icli B, Sun XH, Packard RRS, Esen F, Stapleton CJ, Subramaniam M, Kretschmer K, Apostolou I, von Boehmer H, Hansson GK, Spelsberg TC, Libby P, Feinberg MW: Kruppel-like factor KLF10 targets transforming growth factor-beta 1 to regulate CD4(+)CD25(-) T cells and t regulatory cells. J Biol Chem 2009, 284:24914-24924.

55. Subramaniam M, Gorny G, Johnsen SA, Monroe DG, Evans GL, Fraser DG, Rickard DJ, Rasmussen K, van Deursen JMA, Turner RT, Oursler MJ, Spelsberg TC: TIEG1 null mouse-derived osteoblasts are defective in mineralization and in support of osteclast differentiation in vitro. Mol Cell Biol 2005 25:1191-1199.

56. Tsubone T, Moran SL, Subramaniam M, Amadio PC, Spelsberg TC, An KN: Effect of TGF-beta inducible early gene deficiency on flexor tendon healing. J Orthop Res 2006, 24:569-575.

57. Bensamoun SF, Tsubone T, Subramaniam M, Hawse JR, Boumediene E, Spelsberg TC, An KN, Amadio PC: Age-dependent changes in the mechanical properties of tail tendons in TGF-beta inducible early gene-1 knockout mice. J Appl Physiol 2006, 101:1419-1424.

58. Ma X, Hua J, Mohamood AR, Hamad ARA, Ravi R, Li ZP: A high-fat diet and regulatory $T$ cells influence susceptibility to endotoxin-induced liver injury. Hepatology 2007, 46:1519-1529.
59. Chamulitrat W, Burhenne J, Rehlen T, Pathil A, Stremmel W: Bile saltphospholipid conjugate ursodeoxycholyl lysophosphatidylethanolamide as a hepatoprotective agent. Hepatology 2009, 50:143-154.

60. Pathil A, Warth A, Chamulitrat W, Stremmel W: The synthetic bile acidphospholipid conjugate ursodeoxycholyl lysophosphatidylethanolamide suppresses TNFalpha-induced liver injury. J Hepatol 2011, 54:674-684.

doi:10.1186/1479-5876-12-186

Cite this article as: Kim et al:: Progression of diet induced nonalcoholic steatohepatitis is accompanied by increased expression of kruppel-likefactor 10 in mice. Journal of Translational Medicine 2014 12:186.

\section{Submit your next manuscript to BioMed Central and take full advantage of:}

- Convenient online submission

- Thorough peer review

- No space constraints or color figure charges

- Immediate publication on acceptance

- Inclusion in PubMed, CAS, Scopus and Google Scholar

- Research which is freely available for redistribution

Submit your manuscript at www.biomedcentral.com/submit
C) BioMed Central 